\title{
Amblyopia, deprivation and health disparities research: challenges in 2020
}

\author{
J. Abbott ${ }^{1,2} \cdot$ P. Shah ${ }^{2,3,4,5}$
}

Received: 29 January 2020 / Revised: 7 February 2020 / Accepted: 11 February 2020 / Published online: 24 February 2020

(c) The Royal College of Ophthalmologists 2020

The retrospective study by O'Colmain et al. [1] describes real-world, whole population visual outcomes of 430 children who failed Pre-School Vision Screening (PSVS), in an orthoptist-delivered programme in Scotland. Best-corrected visual acuity, severity of amblyopia and binocular vision were compared at baseline and discharge and measured against (i) the Scottish Index of Multiple Deprivation and (ii) the Health Plan Indicator, which gauges the status of home circumstances. Although overall the PSVS programme was very effective in treating amblyopia, children from more socioeconomically deprived areas or adverse family backgrounds were more likely to attend poorly and be lost to follow-up. Children who were more disadvantaged were more than five times more likely to have residual amblyopia and three times more likely to have poor or no binocular vision.

The concept of multiple deprivation arose from the need to better define the relationship between poverty (a lack of physical resources) and ill-health. In 1979, Townsend [2, 3] argued that a person could be considered to be 'deprived' if they lacked 'the types of diet, clothing, housing, household facilities, fuel, environmental, educational, working and social conditions, activities and facilities that are customary'. The term multiple deprivation reflected the fact that

J. Abbott

joseph.abbott1@nhs.net

1 Department of Ophthalmology, Birmingham Women's \& Children's Hospital, Birmingham, UK

2 Birmingham Institute for Glaucoma Research, Institute of Translational Medicine, University Hospitals Birmingham, Birmingham, UK

3 University of Birmingham NHS Trust, Birmingham, UK

4 Centre for Health and Social Care Improvement, School of Health and Wellbeing, University of Wolverhampton, Wolverhampton, UK

5 University College London, London, UK several types of deprivation could be found occurring simultaneously. The effects of deprivation on individuals and communities are complex. Lane et al. [4] describe a model of the compound (clustering) effects of deprivation at a given time-point, which then become cumulative and have a longitudinal effect over time throughout life.

The burden and unmet needs of amblyopia can be considered at the level of the individual or the population. When testing the individual, amblyopia is usually identified by reduced high-contrast visual acuity but contrast sensitivity, fixation stability, reading speed, and fine-motor coordination are also affected [5]. There are subtle, measurable impacts upon fellow-eye vision such as identification of a shape by motion, known as motion-defined form [6].

The individual with amblyopia in the UK has certain career options excluded depending upon the depth of visual compromise. Exclusions apply in the merchant navy, commercial vehicle driving, emergency services and military roles amongst others [7]. It has been estimated that there is an increased 5-year relative risk of visual loss in the non-amblyopic eye of 2.7 (95\% CI 1.6-4.6) [8] and in particular, of traumatic visual loss [9]. The lifetime risk of bilateral visual impairment is doubled in amblyopia, to about $18 \%$, and where it occurs, the duration is on average, 7.2 years; a not inconsiderable burden [10].

Population studies do not detect a measurable significant impact from amblyopia upon educational, social and health outcomes in the UK [7]. The Blue Mountain Eye Study found lower rates of university qualification amongst the amblyopic group but no difference in lifetime occupational class [8].

Models extrapolating from utility values of acquired visual loss suggest 0.8 QALYs lost over a lifetime [11]. It has been argued that this is an over-estimate because developmental (rather than acquired) visual impact is less impactful [5]. Nonetheless, time-trade-off studies interviewing adults who have experienced amblyopia (and treatment) have produced a similar value of 0.9 QALYs over a lifetime [12]. Tellingly, poor visual outcome correlated most closely with utility 
impact; pointing to the disease and not the treatment as the most important issue.

Amblyopia treatment is cost-effective because treatment costs are low and there is a long life of benefit ahead. The benefit of amblyopia treatment including the consequence of fellow-eye visual loss has been calculated at $\$ 1726$ / QALY (2001 USD values) and on this basis is more than 20 times more cost-effective than hypertension therapy [11].

It is necessary to make assumptions (not universally accepted [5]), regarding disease impact and an individual's economic contribution in order to estimate the 'cost' of amblyopia; calculated at $\$ 7.4$ billion/year [11] in the USA in terms of lost income. This figure can be set against an amblyopia treatment service cost of $\$ 341$ million/year [11].

The significance of O'Colmain's paper is at its clearest when considering the individual. For more deprived children, the outcome from amblyopia is worse. This is an early 'hit' in life, after which disease in the fellow eye may have a catastrophic impact on earnings and economic stability. The bi-directional nature of deprivation and impaired vision is a well described 'poverty trap' [4, 13]. Further 'hits' associated with deprivation are numerous and well documented: in the community (nutrition, age of onset, awareness of disease and reduced screening participation) in primary care (late presentation, reduced access, loss to follow-up) and in hospital eye services (ability to pay for transport, distance from hospital, reduced adherence, poorer equipment) [4].

It is perhaps self-evident that those children with amblyopia who do not attend the Hospital Eye Service will end up with poorer life-long outcomes. Vulnerable children may well have vulnerable parents or carers, with high levels of chaos within their lives. Many children will live in family units in which those responsible for looking after them are struggling to look after themselves. A parent may have tenuous employment, for example with a zero-hours contract - a single visit to hospital at the wrong time in their lives could lead to complete loss of income. It is easy to judge the parents or carers who do not bring their child to clinic, without asking the crucial question: why?

Like all good research, this study raises many important questions. How can we help vulnerable children, who often live with parents and carers who have a state of high geographical mobility? Do their siblings have similar problems? Are there high levels of functional illiteracy amongst the carers responsible for these children? Are the hospital appointment letters even hitting their target or being read?

The complexity of the situation increases when we consider the impact of other important variables which influence healthcare access and behaviour, such as ethnicity. We know that there are there additional barriers for different ethnic groups in accessing healthcare, and the impact of deprivation may be compounded in certain geographical regions, such as the inner cities of large urban conurbations [14]. Understanding the effects of ethnicity requires a strategic ethnically sensitive approach which avoids racialisation [15]. Tadić et al. [16] alert us that children and families from higher levels of socioeconomic deprivation and ethnic minority groups are less likely to participate in visual disability research. There is a significant of proportion of 'silent voices' in many of the communities we serve.

The ability to derive information on multiple deprivation from relatively simple demographic datasets, including the child's postcode, means that we have the tools to identify individuals at risk of deprivation-related poor healthcare outcomes, termed health disparities [17]. One of the insights from the model by Lane et al. of the aggregation of compound and cumulative effects of deprivation on individuals and communities is that there are multiple potential opportunities for intervention, once those individuals are identified. The opportunities for intervention will vary between different communities and targeted strategies are necessary.

The qualitative research paradigm is particularly suited to analysing the complex lives and healthcare behaviours of patients and this is an area that is open to innovative research in amblyopia and deprivation. In order to give all children a better start in life, we first have to look hard at the inequities that exist in society, and make a non-judgemental effort to understand the lives of those we are trying to help by listening to their narratives. Only then can we make real progress.

Health disparities research has significant obstacles to equitable funding, recently highlighted in JAMA [17]. Grants in this area are less likely to be awarded than in other research fields and scientists from ethnic minority groups have a further reduced chance of funding success when working in this area [18]. Far-reaching changes to the way that this work is resourced have been proposed [17] in order to globally maximise the engagement of scientists from under-represented backgrounds. Strategic measures of this nature are a pre-requisite to breaking the cycle of deprivation and vision loss.

\section{Compliance with ethical standards}

Conflict of interest These authors declare that they have no conflict of interest.

Publisher's note Springer Nature remains neutral with regard to jurisdictional claims in published maps and institutional affiliations.

\section{References}

1. O’Colmain U, Neo YN, Gilmour C, MacEwen CJ. Long-term visual and treatment outcomes of whole population Pre-school Visual Screening (PSVS) in children: a longitudinal, retrospective, population-based cohort study. Eye. 2020. (in press). 
2. Townsend P. Deprivation. J Soc Policy. 2009;16:125.

3. Townsend P. Poverty in the United Kingdom; a survey of household resources and standards of Living. Middlesex: Penguin Books Ltd; 1979.

4. Lane M, Lane V, Abbott J, Braithwaite T, Shah P, Denniston AK. Multiple deprivation, vision loss, and ophthalmic disease in adults: global perspectives. Surv Ophthalmol. 2018;63:406-36.

5. Kulp MT, Cotter SA, Connor AJ, Clarke MP. Should amblyopia be treated? Ophthalmic Physiol Opt. 2014;34:226-32.

6. Birch EE, Jost RM, Wang Y-Z, Kelly KR, Giaschi DE. Impaired fellow eye motion perception and abnormal binocular function. Investig Ophthalmol Vis Sci. 2019;60:3374-7.

7. Rahi JS, Cumberland PM, Peckham CS. Does amblyopia affect educational, health, and social outcomes? Findings from 1958 British birth cohort. BMJ. 2006;332:820-5.

8. Chua B. Consequences of amblyopia on education, occupation, and long- term vision loss. Br J Ophthalmol. 2004;88:1119-21.

9. Tommila V, Tarkkanen A. Incidence of loss of vision in the healthy eye in amblyopia. Br J Ophthalmol. 1981;65:575-7.

10. van Leeuwen R, Eijkemans MJC, Vingerling JR, Hofman A, de Jong PTVM, Simonsz HJ. Risk of bilateral visual impairment in individuals with amblyopia: the Rotterdam study. Br J Ophthalmol. 2007;91:1450-1.

11. Membreno JH, Brown MM, Brown GC, Sharma S, Beauchamp GR. A cost-utility analysis of therapy for amblyopia. Ophthalmology. 2002;109:2265-71.
12. van de Graaf ES, van Kempen-du Saar H, Looman CWN, Simonsz HJ. Utility analysis of disability caused by amblyopia and/ or strabismus in a population-based, historic cohort. Graefes Arch Clin Exp Ophthalmol. 2010;248:1803-7.

13. Le Q, Chen Y, Wang X, et al. Analysis of medical expenditure and socio-economic status in patients with ocular chemical burns in East China: a retrospective study. BMC Public Health. 2012; 12:409.

14. Cross V, Shah P, Bativala R, Spurgeon P. ReGAE 2: glaucoma awareness and the primary eye-care service: some perceptions among African Caribbeans in Birmingham UK. Eye. 2006;21: 912-20.

15. Shah P, Cross V. ReGAE 1: using the Shah-Cross model as an orientating framework in African-Caribbean glaucoma research. Eye. 2006;20:988-97.

16. Tadić V, Hamblion EL, Keeley S, Cumberland P, Hundt GL, Rahi JS. 'Silent Voices' in health services research: ethnicity and socioeconomic variation in participation in studies of quality of life in childhood visual disability. Investig Ophthalmol Vis Sci. 2010;51:1886-90.

17. Carnethon MR, Kershaw KN, Kandula NR. Disparities research, disparities researchers and health equity. JAMA. 2019. https://doi. org/10.1001/jama.2019.19329.

18. Hoppe TA, Litovitz A, Willis KA, et al. Topic choice contributes to the lower rate of NIH awards to African-American/black scientists. Sci Adv. 2019;5:eaaw7238. 